\title{
River Restoration in the Twenty-First Century: Data and Experiential Knowledge to Inform Future Efforts
}

\author{
Margaret Palmer, ${ }^{1,2}$ J. David Allan, ${ }^{3}$ Judy Meyer, ${ }^{4}$ and Emily S. Bernhardt ${ }^{5}$
}

\begin{abstract}
Despite some highly visible projects that have resulted in environmental benefits, recent efforts to quantify the number and distribution of river restoration projects revealed a paucity of written records documenting restoration outcomes. Improving restoration designs and setting watershed priorities rely on collecting and making accessible this critical information. Information within the unpublished notes of restoration project managers is useful but rarely documents ecological improvements. This special section of Restoration Ecology is devoted to the current state of knowledge on river restoration. We provide an overview of the section's articles, reflecting on lessons learned, which have implications for the implementation, legal, and financing frameworks for restoration. Our reflections are informed by two databases developed under the auspices of the National River Restoration Science Synthesis project and by extensive inter-
\end{abstract}

actions with those who fund, implement, and permit restoration. Requiring measurable ecological success criteria, comprehensive watershed plans, and tracking of when and where restoration projects are implemented are critical to improving the health of U.S. waters. Documenting that a project was put in the ground and stayed intact cannot be equated with ecological improvements. However, because significant ecological improvements can come with well-designed and -implemented stream and river restorations, a small investment in documenting the factors contributing to success will lead to very large returns in the health of our nation's waterways. Even projects that may appear to be failures initially can be turned into success stories by applying the knowledge gained from monitoring the project in an adaptive restoration approach.

Key words: mitigation, monitoring, restoration, rivers, streams.

\section{Introduction}

At the time of writing this article, most of the land in the United States was no longer in its native state of vegetation and the rate of conversion of land to urban or exurban development was at an all time high (Irwin et al. 2007). By 2030, the United Nations Population Division estimates that $85 \%$ of the U.S. population will live within urban areas (UNPD 2003). Much of the land that has not yet been urbanized is or has recently been in agricultural use (Allan 2004; Moore \& Palmer 2005). Thus, whether we are referring to regions that were once home to boreal forests, vast prairies, or mountainous highlands, human impacts on ecosystems are now so pervasive that few landscapes can be considered "pristine."

As low-lying points, streams and rivers integrate the effects of these changes to the landscape. Of the 5.3

\footnotetext{
${ }^{1}$ Address correspondence to M. Palmer, email mpalmer@umd.edu

${ }^{2}$ University of Maryland Center for Environmental Sciences, Solomons, MD 20688, U.S.A.

${ }^{3}$ College of Natural Resources, University of Michigan, Ann Arbor, MI 48109,

U.S.A.

${ }^{4}$ Institute of Ecology, University of Georgia, Athens, GA 30602, U.S.A

${ }^{5}$ Department of Biology, Duke University, Durham, NC 27708, U.S.A.

million $\mathrm{km}$ of rivers in the coterminous United States, about $79 \%$ are affected by human activities and another $19 \%$ drowned by reservoirs, leaving only $2 \%$ relatively unimpacted river kilometers (Abell et al. 2000; Graf 2001; Wohl et al. 2007). The vast majority (>70\%) of the riparian forests along U.S. rivers and streams have been lost (Innis et al. 2000; Wohl et al. 2007), and more than one-third of the rivers are officially listed as impaired or polluted (EPA 2000). Further, the flood storage capacity of rivers has decreased markedly; water shortages are common throughout the United States; and the diversity of native aquatic wildlife is decreasing (Doppelt et al. 1993; Ricciardi \& Rasmussen 1999; EPA 2000).

Thus, it is easy to understand why stream restoration is important. When rivers and streams are degraded, many of the ecosystem services that are so important to society are lost (Baron et al. 2002). Restoration is an attempt to recoup some of these losses and to do so in more aesthetically pleasing ways and at lower costs than through technological fixes such as waste treatment plants (Palmer et al. 2004). As the National River Restoration Science Synthesis (NRRSS) working group has previously shown, river restoration has increased exponentially in the United States (Fig. 1) largely in response to a greater awareness of the unhealthy state of our 


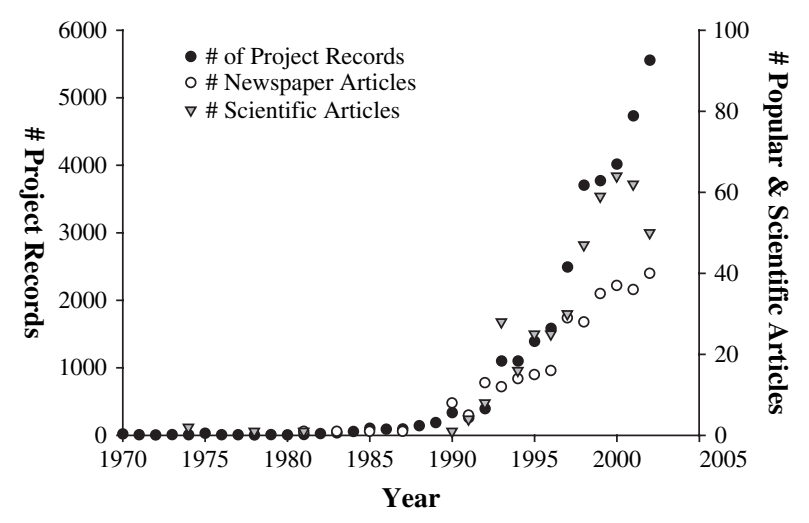

Figure 1. The number of river restoration projects recorded in NRRSS is shown alongside the number of newspaper and scientific journal citations related to stream restoration. Citations were derived from a search for the terms "stream restoration" or "river restoration"in Lexis Nexis Environmental News and ISI Web of Science databases. From Bernhardt et al. (2005). (Reprinted with permission from AAAS [www.sciencemag.org].)

rivers and the impact this has on ecosystems and people (Bernhardt et al. 2005).

This special section of Restoration Ecology is dedicated to the current state of knowledge of river restoration in the United States. For some international perspective, we include one article from work in Australia because the investigators used a study design identical to the NRRSS project. The details of our methods are presented in Bernhardt et al. (2007), which provides a synthesis of our findings from a study that involved in-depth interviews with project managers from representative regions across the country (Fig. 2). Here, we briefly describe what motivated the NRRSS project and provide information on its design and basic findings, reflect on our findings, and then close with a look toward the future of river restoration and how this new knowledge can be applied to meet forthcoming needs.

\section{Methods}

\section{What the Records Say and What the Practitioners Say}

In the fall 2002, a group of river ecologists, geomorphologists, and engineers launched the NRRSS project at a meeting held at the National Center for Ecological Analysis and Synthesis at the University of CaliforniaSanta Barbara. The goal was to bring together scientists engaged in the study of stream restoration to collaboratively articulate the detailed questions that a nationallevel synthesis of river and stream restoration would address, to categorize restoration efforts, and to develop a common set of metrics by which to measure restoration success. During this and subsequent meetings, we invited restoration practitioners from the public and private sectors to join us for 1 or more days to provide new input and to critique our approaches.

The project resulted in the development of two databases (Fig. 3). The "summary database," which was developed using written and electronic records for individual

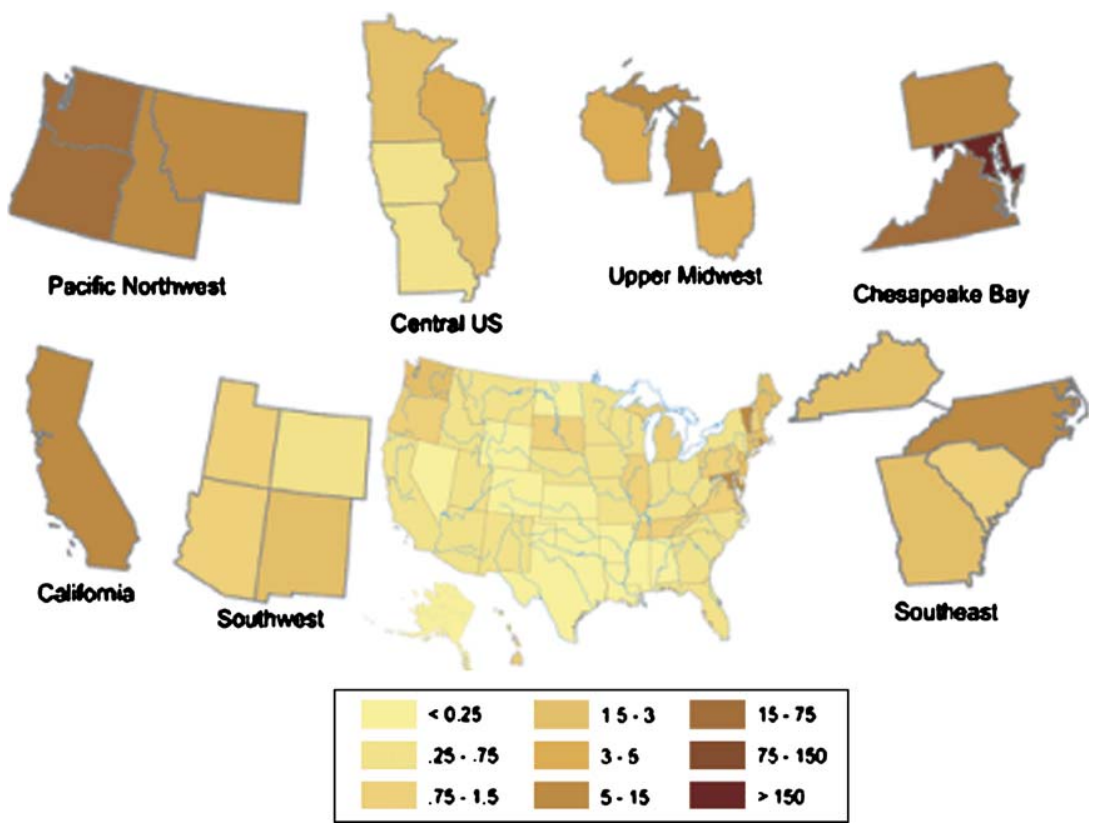

Figure 2. Full U.S. map showing river restoration project density (no. of projects per 1,000 river km) reported in accessible national-level databases (sources provided in table S1, supporting online material from Bernhardt et al. 2005) versus inset regional maps showing density of projects based on in-depth project record summaries collected by the NRRSS team. From Bernhardt et al. (2005). (Reprinted with permission from AAAS [www.sciencemag.org].) 


\section{Steps in Creating the NRRSS Databases}

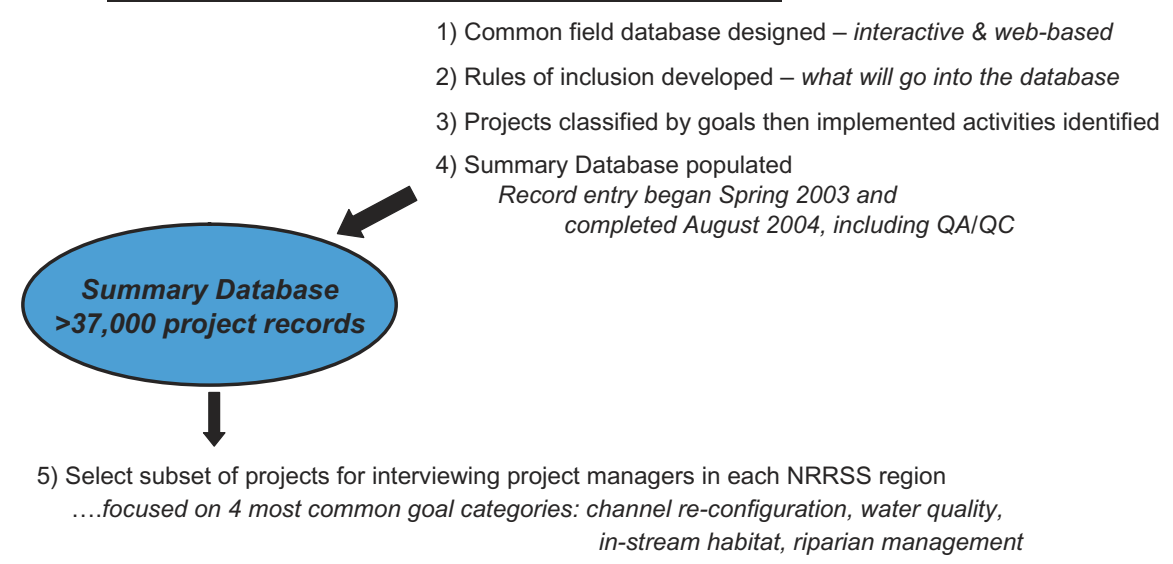

6) Survey/interview protocol designed, tested, and calibrated

7) Complete interviews and populate database

Began interviews in September 2004 and completed by September 2005

Figure 3. Schematic of the process used to develop the two NRRSS databases. The Summary database includes information on projects derived exclusively from written records, whereas the Survey database includes information derived from interviewing project managers. The Summary database is available to the public (www.restoringrivers.org); the interview data are not publicly available due to requirements of the U.S. human subject research protocols.

restoration projects, represents the first comprehensive database for river and stream restoration in the United States. It summarizes basic information (types, costs, etc.) about restoration projects throughout the United States and contains more than 37,000 stream restoration projects, with concentrated data from seven regions of the countryCalifornia, Central United States, Chesapeake Bay, Pacific Northwest, Southeast, Southwest, and Upper Midwest. The results are freely available to scientists and the general public (www.restoringrivers.org). The database can be queried to produce information of special interest, and information on project records can be downloaded.

A national-level synthesis of the status and trends of river restoration was produced (Bernhardt et al. 2005); the policy implications were discussed (Palmer \& Allan 2005); and recommendations for standards for ecological success in restoration were presented (Palmer et al. 2005). Briefly, we show that restoration projects are extremely numerous throughout the country and are being implemented for a variety of reasons using multiple approaches ("activities"; Fig. 4). Expenditures already exceed a billion U.S. dollars per year. Multiple federal, state, and local agencies fund or implement projects, and river restoration is a booming business, demanding more workers and more training programs. However, we show that the science and practice of restoration could be significantly improved by greater assessment of ecological effectiveness and integration with other projects elsewhere in the watershed.
The difficulties in determining which of various restoration actions are most effective (Hassett et al. 2005; Alexander \& Allan 2006) led us, in 2003, to project managers to get more detailed information on project designs, implementation, and outcomes. We developed and calibrated a protocol that was used in all seven regions of the country to interview project managers for a subset of the projects within the Survey Database.

The articles in this special section and Alexander and Allan (2007) report results from these interviews; several articles in this issue also report on regional-level results from the summary database. After a brief overview of the articles, we offer thoughts on what we have learned from practitioners that was difficult to capture with numbers and statistics. Much of what we believe will advance the practice and science of stream and river restoration currently does not lie in numbers and statistics but is within the minds and unpublished notes of the many restoration consultants, watershed experts, and natural resource managers whom we got to know through the NRRSS project.

\section{Results}

\section{Interview Findings}

Bernhardt et al. (2007) provide a national-level synthesis of the results of interviewing 317 restoration practitioners 

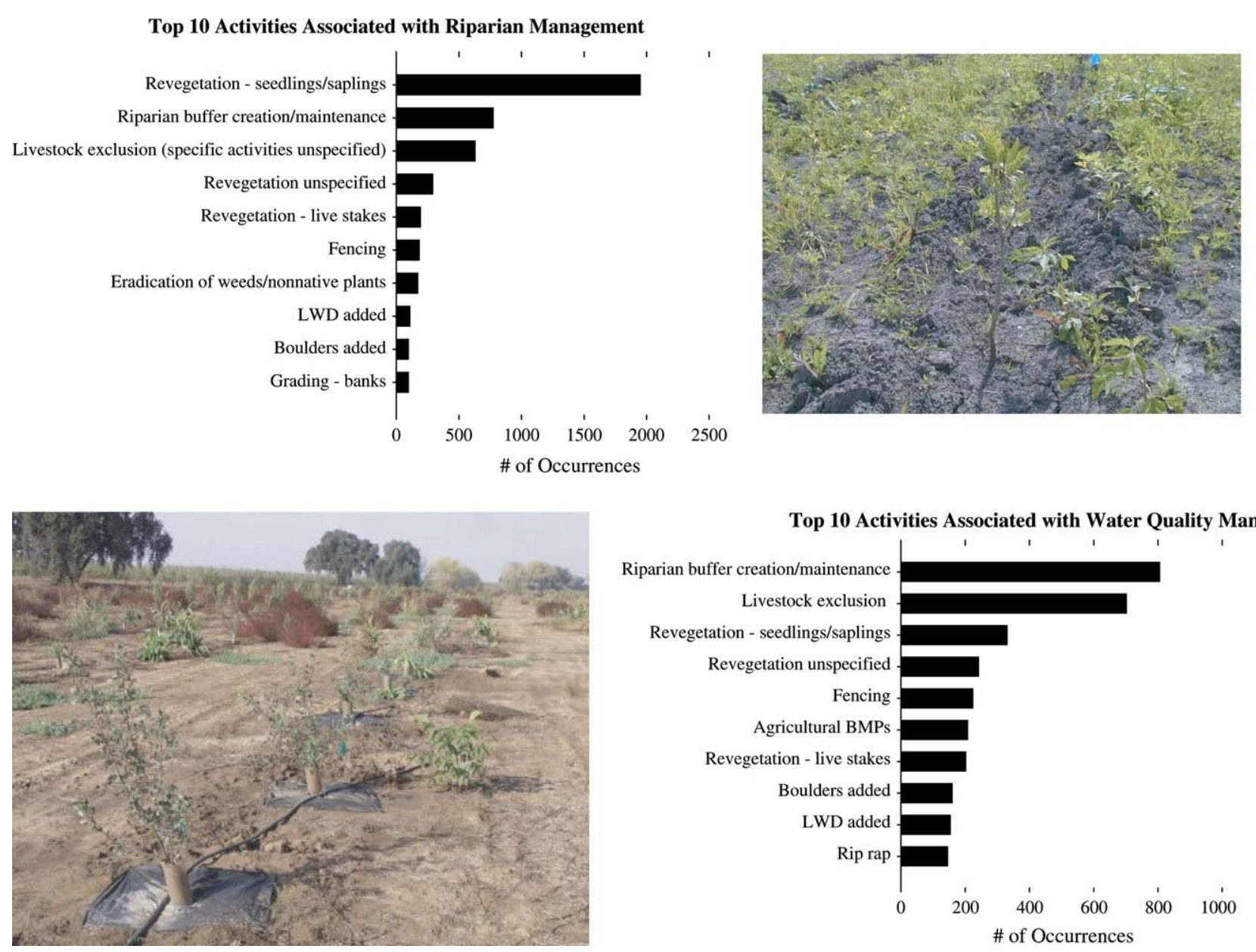

Figure 4. Two of the most common goals of stream and river restoration projects in the United States are to manage the riparian zone and to enhance in-stream habitat. For each goal, a variety of activities (actions) are implemented; some of the activities like planting seedlings are used in almost all restoration projects regardless of the overall project goal.

and project managers. They discuss the relationship between motivations, implementation strategies, and outcome assessments for restoration projects, arguing that the enterprise of river restoration has been weakened by a lack of incentives and requirements for collecting and disseminating information on project outcomes. According to project managers, ecological degradation typically motivated restoration projects, but post-project appearance and positive public opinion were the most commonly used metrics of success. Less than half of all projects set measurable objectives for their projects, but nearly two-third of all interviewees felt that their projects had been "completely successful." Alexander and Allan (2007) reported similar findings for the Upper Midwest and further concluded that when practitioners did collect information on outcome, they had not typically developed a concept of their desired outcome prior to implementing the project.

Katz et al. (2007) show that most projects in the Pacific Northwest of the United States have been focused specifically on the recovery of endangered salmon. They describe a database developed to improve these restoration projects that contain spatially referenced, project-level data on more than 23,000 restoration actions initiated at more than 35,000 locations in the past 15 years. Based on interviews with project managers from a subset of these projects, Rumps et al. (2007) show that almost half the projects in this region of the country lacked success criteria and the majority required adaptive management through on-going maintenance. These results are particularly significant because approximately $60 \%$ of the projects in the NRRSS summary database came from this region alone.

Kondolf et al. (2007) discuss 20 years of river restoration in California. As in the Pacific Northwest, many of these efforts aimed to enhance habitat for anadromous salmonids in the northern half of the state. Although they found that the motivation and funding to initiate restoration projects were much greater than efforts and available funding to monitor or to disseminate lessons learned from projects (a theme throughout the special section), they also encouragingly report that there appears to be 
a transition from traditional engineering approaches to more environmentally oriented practices. We have also observed this anecdotally in our home states (Maryland, Michigan, Georgia).

Tompkins and Kondolf (2007) took the evaluation of restoration efforts in California to a higher level by conducting field-based post-project appraisals of compound channel projects, which incorporate floodplain areas adjacent to the channel to convey floodwaters, enhance riparian habitat, and improve human access and recreational opportunities. They demonstrate that low-effort data collection and analyses can be added to preexisting monitoring programs to yield valuable information on restoration effectiveness for entire classes of projects.

Shifting the focus to the central United States, O'Donnell and Galat (2007) evaluated restoration projects in the Upper Mississippi Basin by comparing goals, activities, and restoration costs in navigated versus nonnavigated rivers and streams. Most navigated river projects addressed the effects of high sedimentation rates through dredging and alteration of flows carrying high amounts of suspended sediment (Fig.5), whereas nonnavigated river projects mostly addressed water quality and riparian problems associated with agriculture. Many of the projects come from U.S. Department of Agriculture databases, and the authors provide a rich history of the role of farming and, not surprisingly, of navigation-related projects by the U.S. Army Corps of Engineers.

Follstad-Shah et al. (2007) describe restoration activities in the Southwestern states of Arizona, New Mexico, Colorado, and Utah. In this region, river restoration plays an important role in attempts to manage non-native species as

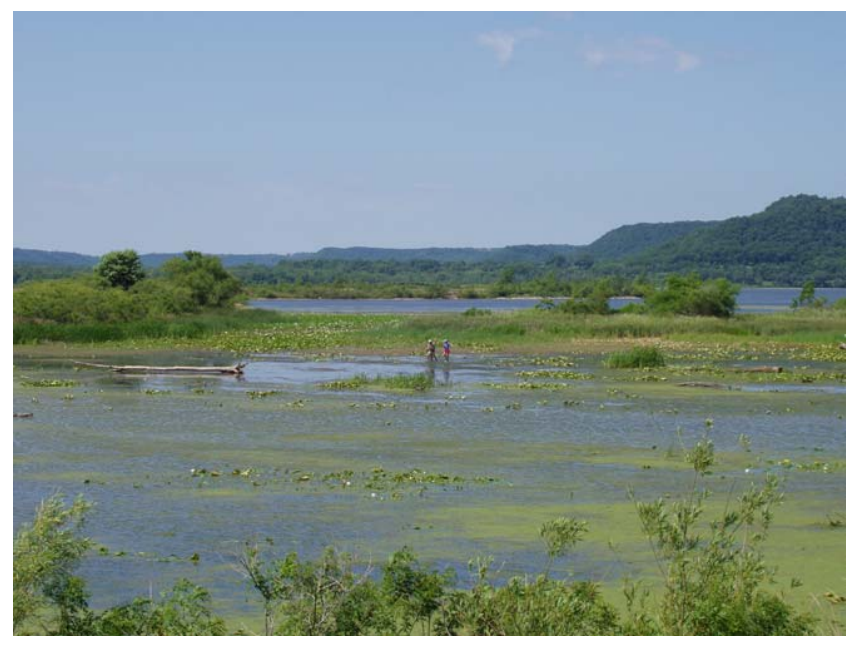

Figure 5. Restoration efforts in the Upper Mississippi River include modifications of backwater areas by restoring barrier islands and controlling flows into side channels. The goal of this project in Winona County, Minnesota, was to reduce high sediment flows entering productive backwater habitats, reduce wind fetch, and enhance rooted aquatic vegetation communities. Photo by T. Kevin O'Donnell. diverse as trout and salt cedar. Although these projects were numerically important, most of the restoration dollars in this region of relative water scarcity have gone to flow modification and water quality management. Monitoring was linked to $28 \%$ of projects across the Southwest, which is high compared to national averages and contrary to public opinion; mean costs of monitored projects were statistically similar those that were not monitored.

Moving east, two papers describe restoration efforts across large regions that differ dramatically in the extent (numbers and expenditures) of restoration efforts. Hassett et al. (2005) previously reported on the large number of stream restoration projects completed in the Chesapeake Bay watershed, showing that riparian management related to concerns over water quality dominate efforts. Interviews with project managers (Hassett et al. 2007) revealed that the majority of projects are monitored to some extent; however, explicit project objectives were typically not reported. An encouraging finding was that one-third of projects were part of a watershed management plan and $70 \%$ were linked to other projects within the same watershed, suggesting cumulative benefits.

In contrast, Sudduth et al. (2007) found a much lower density of projects in the southeast United States, with the exception of the state of North Carolina where mitigation is the primary funding source for stream restoration. Monitoring requirements to earn mitigation credits also contributed to North Carolina having a very high rate of monitoring of stream restoration projects. Many of the southeastern projects are motivated to improve water quality; however, because a large proportion of them involve channel reconfiguration (Fig. 6), the median cost of restoration projects in the southeast is on average much higher (approximately four times) than in the Chesapeake Bay watershed.

The last paper in the special section offers an international perspective. Brooks and Lake (2007), who participated fully in the NRRSS workshops, report on data they compiled on river restoration projects from four catchment management authorities in Victoria, Australia. Due to a restructuring of the reporting and record keeping process for water districts, a great deal of valuable information on project implementation and outcome was recently destroyed. Despite this, they report optimism because of recent advances with mandatory, statewide reporting and an increased emphasis on project design and monitoring.

\section{Discussion}

\section{Data- and Experience-Based Recommendations}

Conclusions from an analysis of both written project records and interviews along with recommendations are provided in all the articles in this special section. However, because we are so constantly asked to provide our opinion on aspects of river restoration for which there are little to no data, we provide the following reflections. These reflections come from our experiences with the 


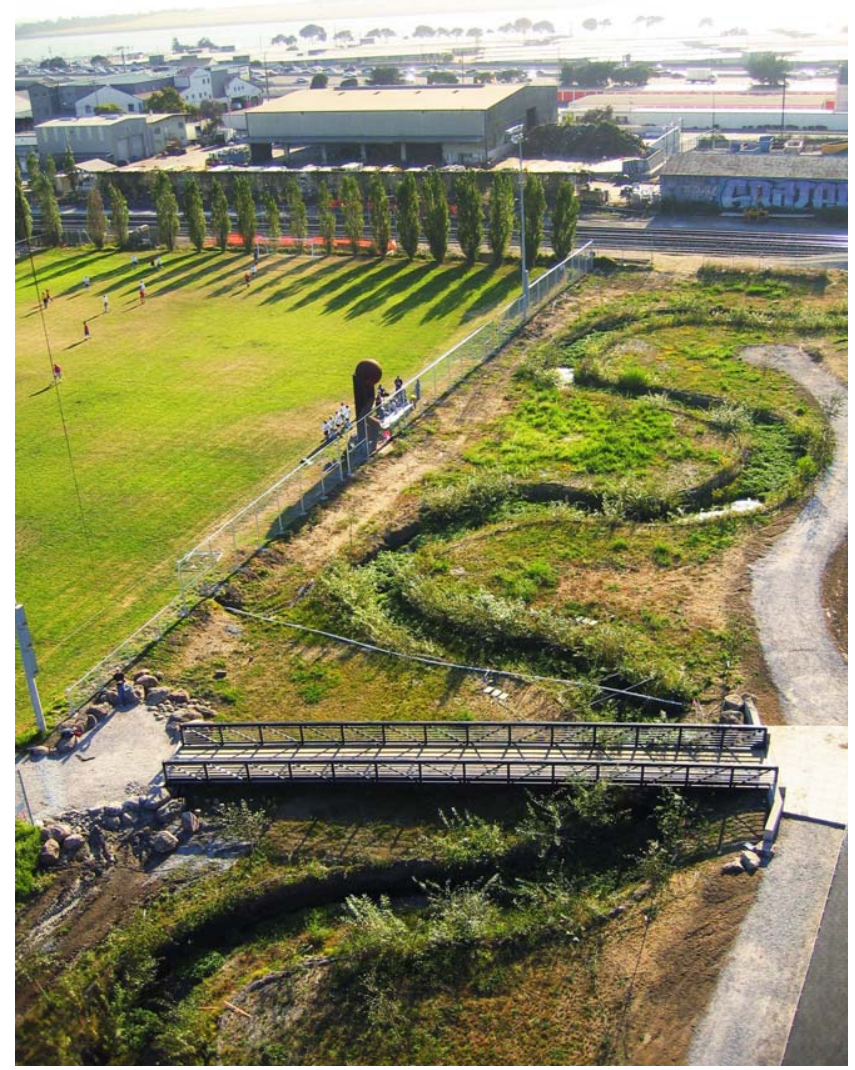

Figure 6. An example of a channel reconfiguration project to restore a 300-m stream reach from a straight, concrete-lined ditch. The high sinuosity design was based on patterns observed on nearby creeks with similar slopes in historical aerial photographs. Since then, the watershed has undergone substantial urbanization, so the project on the Lower Codornices Creek in Berkeley, California, will serve as an experiment to see how this historical shape evolves under changed conditions. Photo by Cris Benton.

NRRSS project, site visits, and discussions about restoration with diverse groups including scientists, design engineers, river advocates, natural resource managers, funding agency and foundation staff, and citizen groups. It is important to point out that our reflections and recommendations apply to restoration projects being done to improve damaged rivers while "doing not harm" (Palmer et al. 2005). Our conclusions and recommendations for restoration efforts being done for mitigation purposes differ from what is given below, most particularly the monitoring component, which will be the subject of a future paper.

\section{Do We Know Why Most Restoration Projects are Implemented?}

Documentation of the need for individual restoration projects is largely lacking. Most projects are initiated based on the advice or actions of one or a few individuals and not based on water quality data or other metrics of impairment. For several regions, we attempted to relate the distribution of restoration projects to the location of streams listed by the states as impaired and found little relationship. Further, a substantial number of projects that are labeled restoration and even paid for by restoration dollars are actually projects to protect infrastructure such as buildings and sewer lines.

Significance. When there is frustration over a lack of realized improvements in water quality or other ecological conditions despite large sums being spent on restoration, it may be because restoration designs were not based on an accurate understanding of the existing problems or because projects were designed for objectives other than ecological restoration.

Recommendation. Guidelines for prioritizing stream and river restoration projects that are based on the distribution and extent of environmental degradation coupled with watershed planning and scientific information on which problems are feasible to address via restoration should be developed and implemented at appropriate scales on a regional basis throughout the country. Such guidelines are already being developed for some regions of the country with great success.

\section{Is There Documentation of Restoration Outcomes?}

Based on conversations with project managers, far more written records on the outcome of restoration projects are kept than we initially reported in Bernhardt et al. (2005) and Hassett et al. (2005). Yet we found that almost all of these are not accessible to the public or even other practitioners. When we inquired about the location of the records, we generally found that their whereabouts were unknown or could not be obtained for logistical reasons. This appears to be primarily due to turnover in personnel with concomitant loss of files, lack of resources for maintaining records, or no organized system for documenting that such a record ever existed or if it does, where it is.

Significance. In the United States, we are not maximizing our collective ability to learn about how to improve ecological outcomes based on past restoration efforts; individual practitioners are gaining knowledge, but this is primarily in the area of structural design outcomes rather than ecological outcomes.

Recommendation. A carefully designed program for strategically monitoring restoration projects to determine which methods in which settings are most ecologically effective is urgently needed (Palmer \& Allan 2005). The results of a collaborative, strategic monitoring program need to be disseminated to practitioners and managers working in the field of restoration. Such programs are easily designed, and scientists and managers around the country are poised to contribute. 


\section{Are Most Practitioners Focused on Profits and Legal Requirements Rather Than Ecological Improvements?}

We have found in many conversations with the public and even with some scientists and managers a general questioning of the motivation of those who implement restoration projects-most often, implementation is by individuals with environmental consulting firms, initiated by project sponsors. Yet, as we conducted our interviews and perhaps more importantly spent time touring restoration sites and attending local workshops and meetings, we generally found that practitioners were highly dedicated individuals with a genuine desire to improve ecological conditions. However, they were often constrained by what project sponsors provided funds to do; funds were generally not provided for ecological premonitoring and rarely for ecological postmonitoring. Any monitoring that was funded was most often limited to visual surveys of the site, photographs, or channel cross-sections.

Significance. It is not practitioners who are at fault with respect to our lack of learning from prior experience, it is "the system"; that is, there has not been a priority on measuring ecological outcomes by policymakers and those who control the funding, permitting, and protocols for restoration (e.g., the U.S. Army Corps of Engineers, federal, state, and local agencies, legislators who authorize funding for programs). The most disturbing finding is that mitigation projects are being permitted with inadequate monitoring.

Recommendation. Clear priorities to document the ecological outcomes of restoration projects should be reflected in the funding, permitting, and regulatory settings at local, state, and federal levels. Funding mechanisms should be established for project outcome documentation. Documentation need not be cumbersome nor extensive for all projects and will lead to immediate benefits for managers and those implementing projects. Projects completed for mitigation are a special case and should be carefully scrutinized prior to permitting to ensure adequate, in-depth (extensive) monitoring of every project.

\section{Is Citizen Involvement Important?}

The best examples we found of well-documented projects in terms of implementation and outcome are those in which citizen groups were involved. In fact, when we tasked ourselves with identifying examples of success "stories" that we could post on our Web site (www. restoringrivers.org), virtually all these were restoration projects with a significant level of involvement of a local watershed association, a neighborhood group, or a student group (Fig. 7).

Significance. Citizens can and do have an incredibly important role to play in river restoration. In many cases, the success of projects or the number of projects in

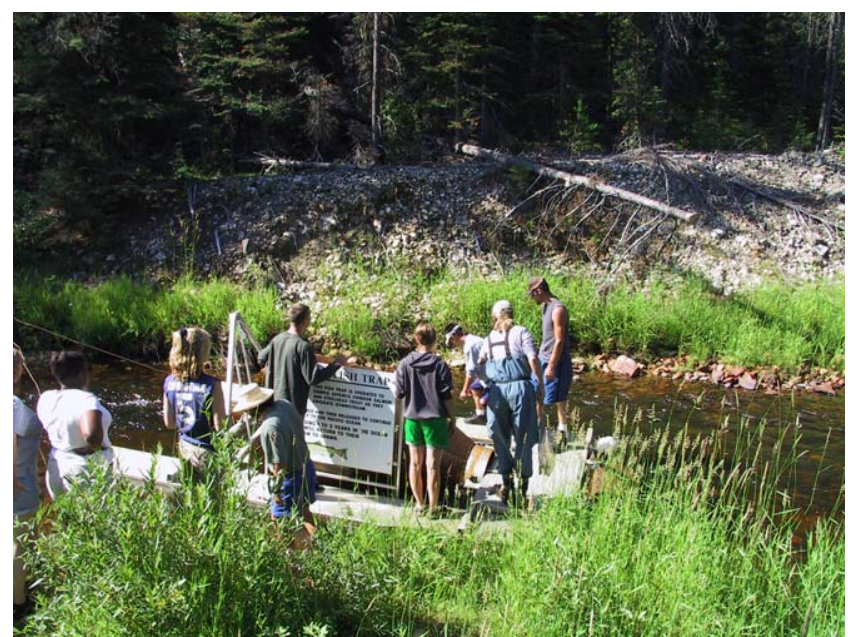

Figure 7. High school students from Idaho and California assist Idaho Department of Fish and Game fisheries biologists with monitoring at a trap for young Chinook salmon, Clearwater River drainage, central Idaho. Photo by Steve Clayton.

a watershed can be traced to the efforts of an individual or a small group of individuals.

Recommendation. The recommendation is to provide mechanisms for ensuring citizen or stakeholder involvement in all restoration projects, even those undertaken by federal agencies. Citizens are excited and willing to participate in projects in virtually all regions of the country.

\section{Will Existing or Improved Restoration Design Manuals and Certification Programs Increase the Ecological Success of River and Stream Restoration?}

New and better designs and education programs are critical because at present, few incorporate ecological principles. Most manuals and training programs have moved beyond a preoccupation with hydraulic engineering and now include important material on geomorphic processes and a few programs have begun to cover ecological processes, showing how they are tied to hydrogeomorphic dynamics in ways that often determine restoration designs (Palmer \& Bernhardt 2006). These are the types of training programs that we believe will lead to the largest improvements in restoration outcome because they provide a basic understanding of how rivers and streams "work." Reliance on design manuals without such understanding can lead to huge failures because restoration outcome depends on the nature of the project within the context of the larger watershed and a site-specific understanding of the geomorphic, hydrologic, and ecological history and future of the river segment. Because rivers are by their very nature always changing, effective restoration almost always involves making adjustments when the river system does not respond as expected or when unexpected events interfere with restoration success; without these adjustments, on-going maintenance will always be required. A useful 
analogy is to consider a physician reattaching a severed limb without determining if the patient's arteries and veins are too damaged to support the limb or without determining if the patient has a compromised immune system or is about to be exposed to extreme conditions that will stress the limb. Even if the physician has this information, he or she often has to adjust the medication or even reset a limb that does not heal properly.

Significance. Streams are living, highly dynamic, and complex systems, each of which has its own history and future. Meticulous engineering design plans for a restoration project do not guarantee success. A project whose design is informed by a basic understanding of the science of stream restoration and an understanding of the current and future context of the stream within the watershed is most likely to succeed.

Recommendation. The restoration permitting process should include a requirement to justify the restoration design and methods in the context of the specific watershed, land use, and hydrogeomorphic setting of the stream or the river. With the exception of mitigation projects, the requirements would be minimal-simply listing all activities to be performed on the application; however, use of highly interventionist methods such as channel reconfiguration or hard engineering should be the last resort and should require special permit applications that document their need over less invasive approaches.

\section{Conclusions}

\section{Restoration Needs of the Future}

As we move further into the twenty-first century, the trend toward more investment in restoration is certain to continue for at least several reasons. First, even where human populations are not growing, water extractions and human infrastructure on the landscape continue to increase dramatically (Alcamo et al. 2006). Second, given future climate projections, many rivers will experience new flow and sediment regimes (Lettenmaier et al. 1999; Poff et al. 2002); yet, it is no longer clear that rivers will have the ability to adjust to these changes in ways that minimize threats to humans and ecosystems (Palmer et al. in press). This is because the dynamic nature of rivers that is fundamental to their ability to absorb disturbances has largely been lost as humans have adapted river systems to their needs (Postel \& Richter 2003). Restoration along with wise management actions can mitigate the expected impacts and perhaps even sustain a river ecosystem's ability to respond to and be resilient in the face of water use and climate change (Palmer et al. in press). For example, restoration of floodplains and wetlands in urban areas could reduce deaths and economic losses from droughts and floods that may be more frequent under future cli- mates. They also produce aesthetically pleasing areas that can be used for recreation.

We posit that the United States and many other countries around the world are at a critical juncture in terms of deciding if we will be proactive and act now to restore ecosystems in order to prevent or minimize future impacts or if we will continue to wait until impacts are felt. The latter reactive approach means attempting to clean up waterways, reintroduce lost native species, stabilize eroded stream banks, and more generally repair damage and replace losses. Which will society choose? A proactive approach would save lives and ecosystems, and although there is some uncertainty concerning which river ecosystems and surrounding regions are at greatest risk, there is enough consensus now to make a great deal of progress. Society cannot approach restoration assuming that uncertainties will ever be reduced to zero; but just as a medical practitioner does not know if a gravely ill patient will respond to medication, the practitioner uses best available knowledge to design a treatment, and if the first approach does not work, one learns from what was tried and adapts the approach or tries something new and then shares the outcome of this information in a publicly accessible form (e.g., journal, online database). This adaptive restoration approach is critical to improving running water ecosystems that are already impacted, but we emphasize that this approach must not be applied to mitigation efforts; additional or new damage to an ecosystem cannot be justified based on restoration unless the latter is known with certainty to be effective and is supported by extensive preand postmonitoring that verifies that ecological functions are replaced.

\section{In Closing}

The end of the NRRSS project is official as of the printing of this special section of Restoration Ecology. The project had discrete goals and a finite period of funding. Although we are continually asked if the NRRSS database (www.restoringrivers.org) will be updated, that was never our intention. We set out to obtain a representative sample of restoration project records and interviews that would allow us to characterize the current state of river restoration in the nation and that is what we accomplished. We do believe that updating the database would be useful and have in fact advocated that national funding be allocated for such an effort (Palmer \& Allan 2005); however, as of this writing, we have seen no evidence that this is likely to happen. It is our hope therefore that a project such as ours will be undertaken at least every decade and that a plan to strategically monitor restoration projects be implemented now. If the recommendations we have made are adopted, then we expect the decadal reports to show significant and consistent improvements in the ecological outcomes of restoration projects and a noticeable increase in the health of our rivers. Despite the environmental problems that we face, it is an exciting time-we are on the cusp of making 
major advances in the practice and science of healing rivers and streams.

\section{Implications for Practice}

- Funding and permitting entities should require that restoration projects identify up front measurable success criteria that are directly linked to the desired outcome of the project. To further ensure project success, funding and permitting entities should be modified to allow monitoring outcomes to be used in an adaptive management approach that helps ensure that the desired project outcome is obtained.

- The development of a comprehensive watershed plan that places each restoration project in its present and future context is essential, where context refers not only to location of the stream but also to its current ecological state and the impacts it is likely to face in the future.

- To maximize success at multiple watershed scales, a restoration project tracking system is essential; at a minimum, the primary project goal (desired outcome), implementation actions that are planned, location, and timing of each project should be entered into the system. Ideally, project outcome should be registered at a later time.

- A larger number of projects must be monitored for ecological outcome using measurable success criteria and that information made accessible. Reporting that a project was implemented as planned or remained physically intact over time is not an indication of ecological success.

- Restoration projects being done for mitigation purposes must only use methods that are known with a high degree of certainty to be effective, and these projects must be supported by extensive pre- and postmonitoring that verifies that ecological functions are replaced.

\section{Acknowledgments}

We could not have completed this project without the support and input of a number of colleagues from American Rivers, the most prominent river conservation organization in the country. We particularly thank K. Ransel, M. Bowman, and A. Fahlund. We thank the following for their support of the NRRSS project (www.nrrss.umd.edu): the University of Maryland, the State of Maryland's Department of Natural Resources, the Lucille and David Packard Foundation, the National Center for Ecological Analysis and Synthesis, the Charles S. Mott Foundation, CALFED, the Altria Foundation, and the United States Geological Survey" National Biological Information Infrastructure program. This paper is Contribution number 4093 from the University of Maryland Center for Environmental Science.

\section{LITERATURE CITED}

Abell, R. A., D. M. Olson, E. Dinerstein, P. T. Hurley, J. T. Diggs, W. Eichbaum, et al. 2000. Freshwater ecoregions of North America: a conservation assessment. Island Press, Washington, D.C.

Alcamo, J., M. Floerke, and M. Maerker. 2007. Future long-term changes in global water resources driven by socio-economic and climatic changes. Hydrological Science 52:247-275.

Alexander, G. G., and J. D. Allan. 2007. Stream restoration in the Upper Midwest, USA. Restoration Ecology 14:595-604.

Alexander, G. G., and J. D. Allan. 2007. Ecological success in stream restoration: case studies from the Midwestern U.S. Environmental Management, doi: 10.1007/s00267-006-0064-6.

Allan, J. D. 2004. Landscapes and riverscapes: the influence of land use change on stream ecosystems. Annual Review of Ecology, Evolution, and Systematics 35:257-284.

Baron, J. S., N. L. Poff, P. L. Angermeier, C. N. Dahm, P. H. Gleick, N. G. Hairston, R. B. Jackson, C. A. Johnston, B. G. Richter, and A. D. Steinman. 2002. Meeting ecological and societal needs for freshwater. Ecological Applications 12:1247-1260.

Bernhardt, E. S., E. B. Sudduth, M. A. Palmer, J. D. Allan, J. L. Meyer, G. Alexander, et al. 2007. Restoring rivers one reach at a time: results from a survey of U.S. river protection practitioners. Restoration Ecology 15:482-494.

Bernhardt, E. S., M. A. Palmer, J. D. Allan, G. Alexander, K. Barnas, S. Brooks, et al. 2005. Synthesizing US river restoration efforts. Science 308:636-637.

Brooks, S. S., and P. S. Lake. 2007. River restoration in Victoria, Australia: change is in the wind, and none too soon. Restoration Ecology 15:583-590.

Doppelt, B., M. Scurlock, C. Frissell, and J. Karr. 1993. Entering the watershed: a new approach to save America's river ecosystems. Island Press, Washington, D.C.

EPA. 2000. National water quality inventory. EPA Publ. 841-R-02-001. Environmental Protection Agency, Washington, D.C.

Follstad Shah, J. J., C. N. Dahm, S. P. Gloss, and E. S. Bernhardt. 2007. River and riparian restoration in the Southwest: results of the National River Restoration Science Synthesis Project. Restoration Ecology 15:550-562.

Graf, W. L. 2001. Damage control: restoring the physical integrity of America's rivers. Annals of the Association of American Geographers 91:1-27.

Hassett, B., M. Palmer, E. Bernhardt, S. Smith, J. Carr, and D. Hart. 2005. Restoring watersheds project by project: trends in Chesapeake Bay tributary restoration. Frontiers in Ecology and the Environment 3:259-267.

Hassett, B. A., M. A. Palmer, and E. S. Bernhardt. 2007. Evaluating stream restoration in the Chesapeake Bay watershed through practitioner interviews. Restoration Ecology 15:563-571.

Innis, S. A., R. J. Naiman, and S. R. Elliott. 2000. Indicators and assessment methods for measuring the ecological integrity of semi-aquatic terrestrial environments. Hydrobiologia 422/423:111-131.

Irwin, E. G., H. J. Cho, and N. E. Bockstael. 2007. Measuring the amount and pattern of land development in non-urban areas. American Journal of Agricultural Economics (in press).

Katz, S. L., K. Barnas, R. Hicks, J. Cowen, and R. Jenkinson. 2007. Freshwater habitat restoration actions in the Pacific Northwest: a decade's investment in habitat improvement. Restoration Ecology 15:494-505.

Kondolf, G. M., S. Anderson, R. Lave, L. Pagano, A. Merelender, and E. S. Bernhardt. 2007. Two decades of river restoration in California: what can we learn? Restoration Ecology 15:516-523.

Lettenmaier, D. P., A. W. Wood, R. N. Palmer, E. F. Wood, and E. Z. Stakiv. 1999. Water resources implications of global warming: a U.S. regional perspective. Climate Change 43:537-579. 
Moore, A. M., and M. A. Palmer. 2005. Agricultural watersheds in urbanizing landscapes: implications for conservation of biodiversity of stream invertebrates. Ecological Applications 15:1169-1177.

O'Donnell, T. K., and D. L. Galat. 2007. River enhancement in the upper Mississippi River basin: approaches based on river uses, alterations, and management agencies. Restoration Ecology 15:538-549.

Palmer, M. A., and J. D. Allan. 2005. Restoring rivers. Issues in Science and Technology 22:40-48.

Palmer, M. A., and E. S. Bernhardt. 2006. Hydroecology and river restoration: ripe for research and synthesis. Water Resources Research 42: W03S07, doi:10.1029/2005WR004354.

Palmer, M. A., E. S. Bernhardt, J. D. Allan, P. S. Lake, G. Alexander, S. Brooks, et al. 2005. Standards for ecologically successful river restoration. Journal of Applied Ecology 42:208-217.

Palmer, M. A., E. Bernhardt, E. Chornesky, S. Collins, A. Dobson, C. Duke, et al. 2004. Ecology for a crowded planet. Science 304:1251-1252.

Palmer, M. A., C. Reidy, C. Nilsson, M. Florke, J. Alcamo, P. S. Lake, and N. Bond. 2007. Climate change and the world's river basins: anticipating response options. Frontiers in Ecology and the Environment (in press).

Poff, N. L., M. M. Brinson, and J. W. Day. 2002. Aquatic ecosystems and global climate change: potential impacts on inland freshwater and coastal wetland ecosystems. Prepared for the Pew Center on
Global Climate Change. Arlington, VA. (available from www. pewclimate.org/projects/aquatic.clim) accessed 20 June 2007.

Postel, S., and B. Richter. 2003. Rivers for life: managing water for people and nature. Island Press, Washington, D.C.

Ricciardi, A., and J. B. Rasmussen. 1999. Extinction rates of North American freshwater fauna. Conservation Biology 13:1220-1222.

Rumps, J. M., S. L. Katz, K. Barnas, M. D. Morehead, R. Jenkinson, S. R. Clayton, and P. Goodwin. 2007. Stream restoration in the Pacific Northwest: analysis of interviews with project managers. Restoration Ecology 15:506-515.

Sudduth, E. B., J. L. Meyer, and E. S. Bernhardt. 2007. Stream restoration practices in the southeastern US. Restoration Ecology 15:572-582.

Tompkins, M. R., and G. M. Kondolf. 2007. Systematic post-project appraisals to maximize lessons learned from river restoration projects: case study of compound channel restoration projects in Northern California. Restoration Ecology 15:524-537.

UNPD. 2003. United Nations Population Division, World Population Prospects: the 2002 Revision, Highlights (online database). ESA/P/ WP.180, revised 26 February 2003 (available from www.un.org/ esa/population/publications/wpp2002/wpp2002-Highlightsrevl.pdf) accessed 20 June 2007.

Wohl, E., M. A. Palmer, and J. M. Kondolf. 2007. The U.S. experience. Chapter 10. In G. J. Brierley, and K. A. Fryirs, editors. River futures. Island Press, Washington, D.C. (in press). 